\title{
ECHINOCOCCUS MULTLOCULARIS INFECTIONS OF RURAL, RESIDENTIAL AND URBAN FOXES (VULPES VULPES) IN THE CANTON OF GENEVA, SWITZERLAND
}

\author{
FISCHER C.*, REPERANT L.A.**, WEBER J.M.***, HEGGLIN D.*** \& DEPLAZES P.**
}

\section{Summary: $\mathrm{s}$}

We examined 267 red foxes (Vulpes vulpes) from the canton of Geneva, Switzerland, for intestinal infections with Echinococcus multilocularis. This region is situated in the core area of the endemic range of this zoonotic cestode in Central Europe. Several factors were taken into account and urbanisation level appeared to be the most explicative to describe observed differences. The prevalence decreased significantly from rural and residential areas lprevalence of $52 \%, \mathrm{Cl} 43-62 \%$, and $49 \%, \mathrm{Cl} 38-59 \%$, respectively) to the urban area (prevalence of $31 \%, \mathrm{Cl} 19-42 \%$ ). A few juvenile foxes harboured very high burdens up to more than 120,000 worms and were significantly more heavily infected than adults. The intensity of infection decreased from rural and residential areas to the city, suggesting a lower contamination of the urban environment.

KEY WORDS : Echinococcus multilocularis, Vulpes, red fox, urbanisation, zoonosis, Switzerland.

\section{INTRODUCTION}

T The small fox tapeworm Echinococcus multilocularis is one of the most serious zoonotic helminths leading to alveolar echinococcosis in humans (Eckert \& Deplazes, 2004; Giraudoux et al., 2001; Vuitton et al., 2003). This liver disease caused by the metacestode stage of E. multilocularis is rare (0.02 to 1.4 cases per 100,000 inhabitants in Europe, Vuitton et al., 2003, 11 to 40 cases per 100,000 inhabitants in endemic foci), but severe with a fatal outcome if left untreated (Amman \& Eckert, 1995). Gottstein (1992) concluded that $56 \%$ to $94 \%$ of declared and untreated cases of alveolar echinococcosis result in death, and letality was still $10 \%$ to $14 \%$ when early diagnosed and treated.

The cestode E. multilocularis is a dixenous helminth with carnivores as definitive hosts. E. multilocularis is maintained in a wild animal cycle including red foxes

\footnotetext{
* Université de Lausanne, Département d'écologie et évolution, Bâtiment de biologie, 1015 Lausanne, Switzerland.

** Institute of Parasitology, University of Zurich, Switzerland.

*** KORA, Thunstrasse 31, 3074 Muri b. Bern, Switzerland.

Correspondence: Claude Fischer, rue F. Soguel 14, CH-2053 Cernier.

Tel.: ++41327246888 - Fax: ++41227591405.
}

Résumé : ECHINOCOCCOSE ALVÉOLAIRE CHEZ LE RENARD ROUX, EN MiLIEUX RURAL, RÉSIDENTIEl ET uRBANISÉ, DANS LE CANTON DE GENÈVE, SuISSE

Nous avons examiné 267 renards Nulpes vulpes) provenant du canton de Genève, Suisse, en vue d'évaluer le taux d'infection par le cestode Echinococcus multilocularis. Cette région est située au coeur de l'aire de distribution européenne de cet helminthe zoonotique. Nous avons considéré plusieurs facteurs potentiels et le taux d'urbanisation est apparu être le plus explicatif. La prévalence diminue significativement des zones rurale et résidentielle en allant vers la zone urbaine. Quelques individus juvéniles abritaient de très hautes charges parasitaires allant jusqu'à plus de 120000 vers et ils étaient significativement plus infectés que les adultes. La charge parasitaire allait en diminuant du secteur rural vers les secteurs résidentiels et urbains, ce qui suggère une contamination de l'environnement plus faible en milieu urbain.

MOTS CLÉS : Echinococcus multilocularis, Vulpes, renard roux, urbanisation, zoonose, Suisse.

as definitive hosts and a range of rodents as intermediate hosts (Eckert \& Deplazes, 2004; Vuitton et al., 2003). Domestic dogs and cats are also potential definitive hosts (synanthropic transmission) though at a much lower extent (Eckert et al., 2001a; Gottstein et al., 2001). However, in Europe, red foxes are considered as the main source of contamination of the environment (Eckert \& Deplazes, 2004).

After the successful vaccination campaigns against rabies, red fox populations in Western and Central Europe recovered to densities similar to what was observed before the epidemics, or even increased (Breitenmoser et al., 1995) according to a trend towards an increase already observed before the rabies epidemic (Chautan et al., 1998). A new phenomenon appeared at the same time: as already observed in Great Britain several decades before (Macdonald \& Newdick, 1982), red foxes began to colonize cities and by now "urban foxes", with populations living and reproducing in the cities, are also a reality in continental Europe (Gloor et al., 2001a; Deplazes et al., 2004).

Red foxes in urban areas are often more abundant than in rural or natural habitats (Harris, 1981; Gloor et al., 2001b), and have closer contact with humans. This proximity and the observed densities are a concern for 
public health. E. multilocularis could thus represent a public health risk especially for urban inhabitants. However, because of a subsequent incubation of five to 15 years in humans, the correlation between the increased risk related to fox population new dynamics and a potential increase in the incidence of alveolar echinococcosis is difficult to assess at that time (Deplazes et al., 2004).

Only few studies have so far been conducted in urban areas of Central Europe to investigate transmission of E. multilocularis. What is interesting in Geneva, is that the situations in neighbouring France (Pétavy et al., 1990) and Switzerland (Siegenthaler \& Brossard, 1996) are already documented. In addition, the structure of the city ( $c f$. study area) and the apparently less appropriate climate for the survival of Echinococcus eggs (warmer and drier conditions as compared to surrounding rural areas) known as the Urban Heat Island effect (Shashua-Bar \& Hoffman, 2000; Unger et al., 2001) also make Geneva a unique study opportunity. Furthermore, a preliminary study, conducted on a small sample size $(\mathrm{N}=160$ foxes) already identified the presence of the small-fox tapeworm in the canton of Geneva, and showed a difference along a gradient of variable human density (Fischer et al., 2003). However, the method used to differentiate urban, residential and rural areas was not precise enough. The method used in the city of Zurich is not satisfactory either, with a "border zone" being considered arbitrarily to have a width of $250 \mathrm{~m}$ between urban and rural zones (Stieger et al.,
2002). This method determines a buffer area rather than a real identifiable residential habitat.

In this paper, E. multilocularis prevalence and abundance were investigated following a gradient of urbanisation.

\section{STUDY AREA}

The canton of Geneva is located at the western tip of Switzerland, at the end of the lake Geneva (Fig. 1). Altitudes range between 350 and $500 \mathrm{~m}$ and the climate is temperate with a Mediterranean influence. Average annual rainfall is less than $900 \mathrm{~mm}$ and mean temperatures is around $12^{\circ} \mathrm{C}$. Mean relative humidity is less than $75 \%$ (Annuaire statistique du canton de Genève, 2003). Snow periods are rare and if snow is present, there are only a few centimetres and it rarely lasts for more than a couple of days.

The canton is highly urbanised, with 400,000 inhabitants living in an area of $240 \mathrm{~km}^{2}$. Over $84 \%$ of the inhabitants live in the agglomeration of Geneva itself, which is located in the centre of the canton, around the end of the lake. The rest of the population is scattered within 16 small villages. The urbanized areas account for half the canton's area, the rest is mostly devoted to intensive agriculture (cereal crops and vineyards) and has a limited portion of permanent grassland (18.6 \%). Forests represent less than $10 \%$ of the area. An extensive road network with heavy traffic criss-crosses the rural areas and forests.

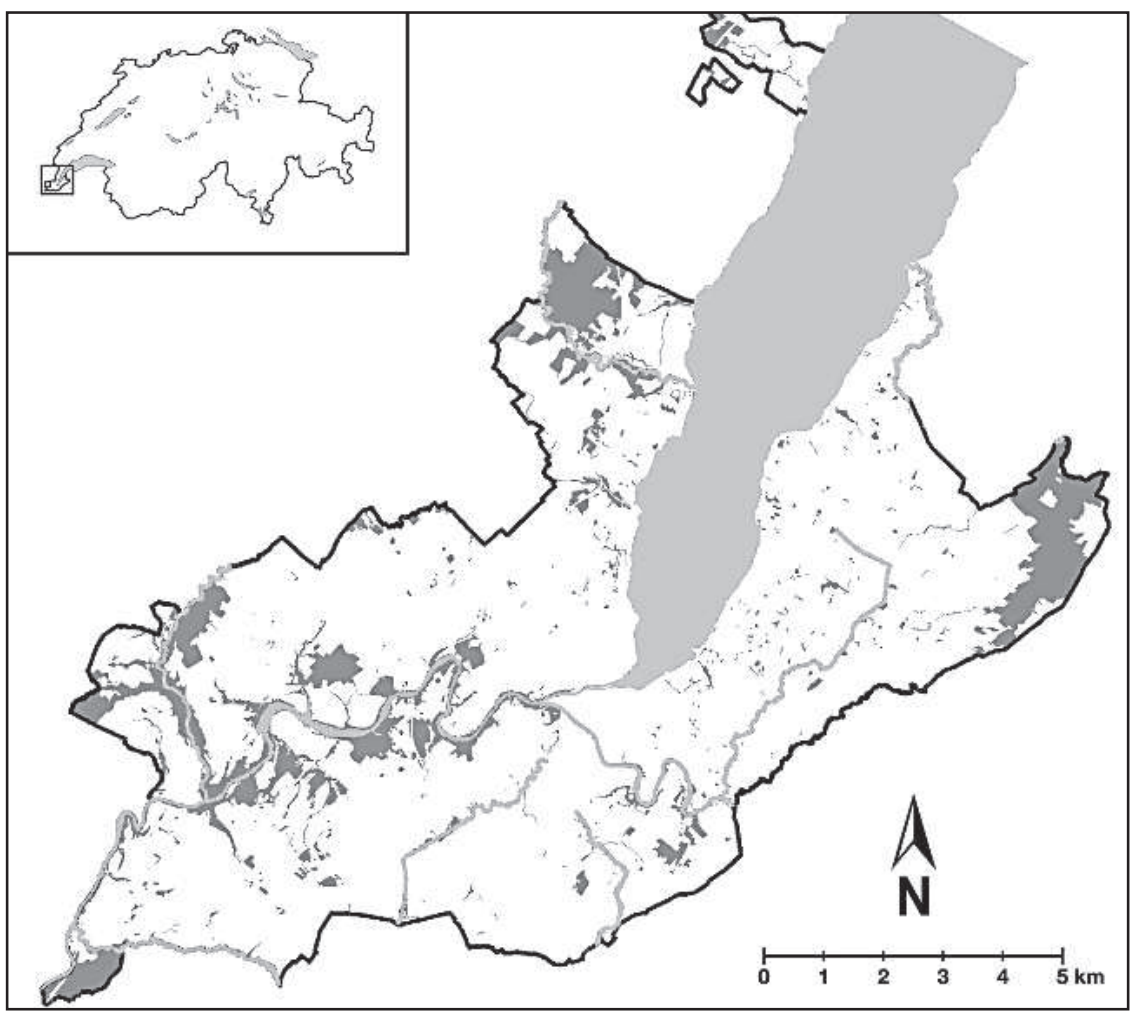

Fig. 1. - Situation of the canton of Geneva. 
The agglomeration of Geneva is characterized by a particularly extensive residential area organised as a belt around the core of the city. Individual housing with private gardens accounts for $20 \%$ of the canton's area (cf. methods). Its width ranges from $200 \mathrm{~m}$ to $2 \mathrm{~km}$. This zone appears to be particularly favourable for the red fox, as it provides abundant food and shelter possibilities. Furthermore, the shores of the lake and riverbanks constitute sheltered corridors for the movements of the fauna and give it the possibility to penetrate deep into the core of the city.

\section{METHODS}

\section{SAMPLING OF FOXES}

I $\mathrm{n}$ the canton of Geneva hunting was abolished in 1974. Only game keepers are allowed to shoot animals. Regarding red fox management, only individuals which are injured, sick or which pose recurrent problems are shot. Game keepers also collect all wild animals found dead. Data collection is not bound to hunting pressure and the collaboration of hunters. Data collection is thus similar from year to year.

Dead and shot foxes were collected all over the canton from 1998 onward. They were located exactly on a map or by GPS, weighed and sexed. Age and reproductive status were defined. Age was determined counting annuli in the cementum of the canine of the lower jaw. Age in months was calculated assuming birth date being the first of April (Wandeler, 1976). Foxes are considered juveniles when less than one year old. Carcasses were dissected and organs collected and deep frozen for four days at $-80^{\circ} \mathrm{C}$ following safety precautions described in Eckert et al. (2001c), and then conserved at $-20^{\circ} \mathrm{C}$. before further analysis. The digestive tract was isolated from the pyloric sphincter to the anus.

\section{E. MULTILOCULARIS DETECTION}

E. multilocularis was recovered with the intestinal sedimentation and counting technique (SCT). Species identification was based on typical morphological characteristics. The sediment fraction was examined in small portions of about $5 \pm 10 \mathrm{ml}$ in square Petri dishes. If more than 100 worms were found the total worm burden was calculated from the count of one subsample (for details: Hofer et al., 2000).

Aggregation was measured using the corrected moment estimate of $\mathrm{k}$ as:

$$
\mathrm{k}=\left(\mathrm{x}^{2}-\mathrm{S}^{2} / \mathrm{N}\right) /\left(\mathrm{S}^{2}-\mathrm{x}\right)
$$

where $\mathrm{x}$ is mean of intensity, $\mathrm{S}^{2}$ is variance of intensity and $\mathrm{N}$ is sample size, as described in Elliot (1977).
Confidence interval (95\%) of prevalence was calculated as:

$$
95 \% \mathrm{CI}=1.96[(\mathrm{p}(1-\mathrm{p})) / \mathrm{N}]^{1 / 2}
$$

where $\mathrm{p}$ is prevalence and $\mathrm{N}$ is sample size. Intensity of infection refers to parasite distributions in infested animals only.

\section{URBANISATION}

Regarding urbanisation, we defined three different sectors: rural, residential, and urban. We considered the total number of inhabitants of private housing and of employees working in industries, offices and administrations, i.e. the number of persons registered at a given adress (following data of the cantonal administration based on a population census made in summer 2002), and selected a grid of squares of $100 \times 100 \mathrm{~m}$. Rural sectors were then defined by a human density of $\leq 40$ people per $\mathrm{km}^{2}$ during the day or night, residential areas by a density ranging between 40 and 220 humans per $\mathrm{km}^{2}$, and urban areas by a density of more than 220 human per $\mathrm{km}^{2}$ (maximum density being 3,790). The three resulting concentric areas, with the most urbanised, the city, in the core and around the end of the lake, then a belt of residential area, and finally, the rural areas towards the borders of the canton (Fig. 2) were smoothed with the adaptive Kernel method (applied with the least-squares crossvalidation as smoothing parameter; Worton, 1989). Several small villages scattered within the rural area represent residential islands. In the south, the residential area continues towards France up to the small town of Annemasse, interrupting the surrounding rural sectors.

\section{STATISTICAL ANALYSIS}

Statistical analyses were performed with SPSS-PC version 10.0. To evaluate the effect of urbanisation on E. multilocularis prevalence in foxes, irrespective of potentially confounding variables, a multiple logistic regression model was calculated with the factors year, season (winter: December to February; spring: March to May; summer: June to August; fall: September to November), age (juvenile or adult) and sex. Furthermore, as $27 \%$ of the investigated foxes were infected with sarcoptic mange, and as it could bias dead fox sampling procedure, the factor mange (infected or not infected) was added to the model. In a second step the factor urbanisation sector was added to the full model and the difference of the two models was tested by a Log-Likelihood test. Finally, a stepwise backward procedure (using likelihood ratio) was performed to find the most relevant factors affecting the E. multilocularis prevalence. The Mann-Whitney U-test was applied for the comparison of parasite distribution (intensity of infection), or age distribution in months. Tests were considered significant when $\mathrm{p}<0.05$. 


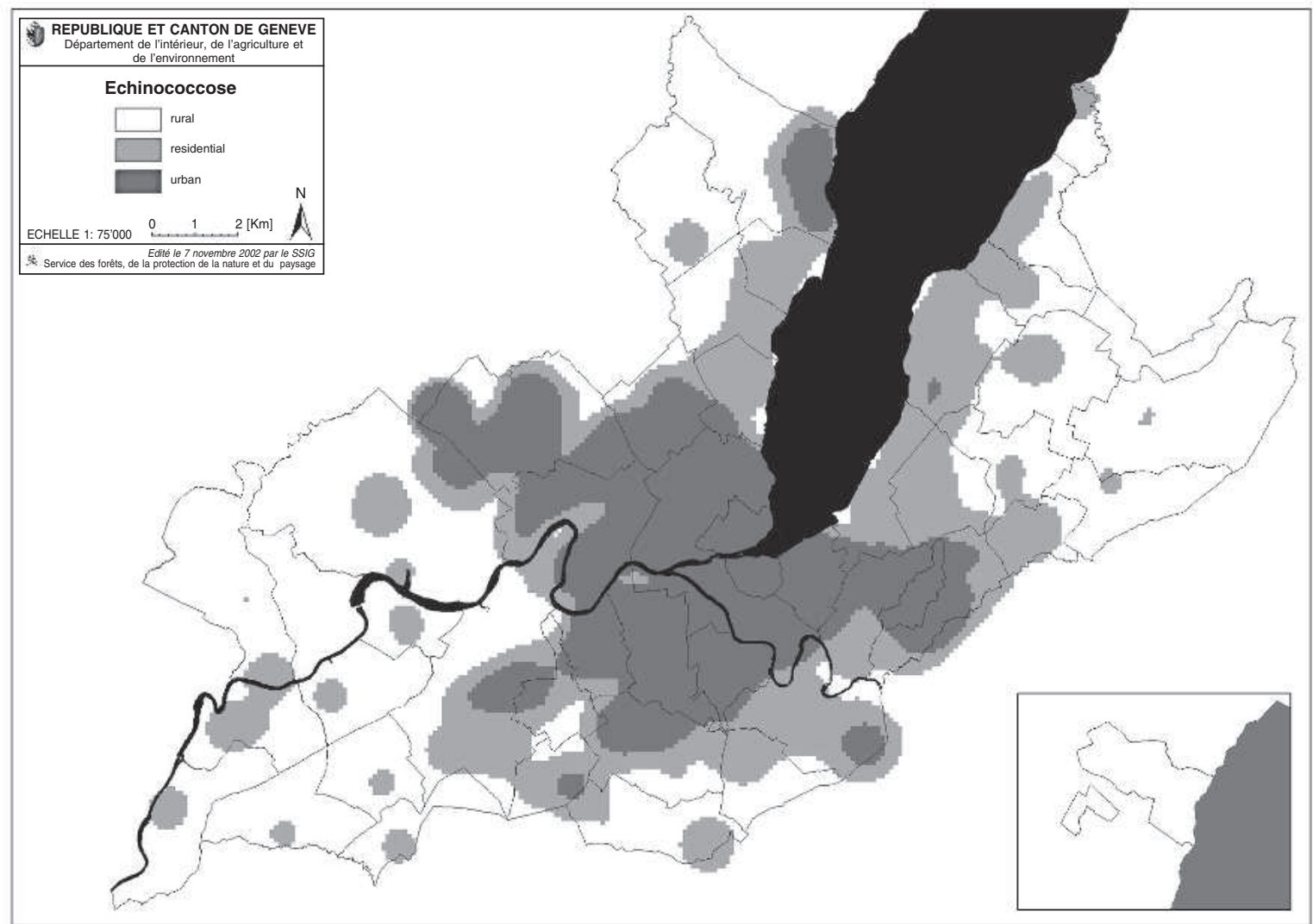

Fig. 2. - Representation of the three considered areas: white $=$ rural; light grey $=$ residential; dark grey $=$ urban.

\section{RESULTS}

\section{RED FOXES}

F rom January 1998 to December 2002, 454 red foxes, found dead or shot were collected from all parts of the canton of Geneva, but only 267 could be analysed for parasitical survey. Mortality was mainly due to collisions with vehicles (over $75 \%$ of instances) and often it was not possible to collect intact inner organs, or carcasses were too old to be evaluated. Sex and age were determined for 253 animals, distributed in 137 males and 116 females. Juveniles counted for 134 animals and adults for 119 .

A total of 103 carcasses came from the rural area, 88 from the residential area and 62 from the urban area; location of 14 remaining foxes was not known. No statistical difference in age (ratio juveniles:adults) or sex distribution between the three urbanization areas was detected.

\section{Prevalence of E. Multilocularis}

E. multilocularis was recovered at a prevalence of $45.7 \%$ in red foxes from the canton of Geneva. A full logistic regression model revealed significant differences of $E$. $m u l$ tilocularis prevalence between the different years and between the different urbanisation sectors (Table I). A Log-Likelihood test revealed that the addition of the factor urbanisation sector improved the model only at

\begin{tabular}{lccc}
\hline $\begin{array}{l}\text { Explanatory variables } \\
\text { (test category/ } \\
\text { reference categorie) }\end{array}$ & OR & $\begin{array}{c}\mathbf{9 5} \mathbf{\%} \mathbf{C I} \\
\text { for } \mathbf{~ O R}\end{array}$ & P-value \\
\hline $\begin{array}{l}\text { Sex } \\
\text { male/female }\end{array}$ & 1.22 & $0.69-2.13$ & 0.498 \\
$\quad$ Age & & & \\
$\quad$ adult/juvenile & 0.84 & $0.47-1.49$ & 0.556 \\
Mange & & & \\
yes/no & 0.92 & $0.49-1.69$ & 0.786 \\
Season & & & 0.229 \\
Dec.-Feb./Sep.-Nov. & 1.44 & $0.59-3.44$ & 0.418 \\
Mar.-May./Sep.-Nov. & 0.86 & $0.38-1.95$ & 0.727 \\
Nov.-Aug./Sep.-Nov. & 1.89 & $0.79-4.47$ & 0.151 \\
Year & & & 0.062 \\
1998/2002 & 0.58 & $0.25-1.34$ & 0.205 \\
1999-2002 & $\mathbf{0 . 3 6}$ & $\mathbf{0 . 1 5}-\mathbf{0 . 8 3}$ & $\mathbf{0 . 0 1 8}$ \\
2000/2002 & 0.39 & $0.15-1.02$ & 0.056 \\
2001-2002 & $\mathbf{0 . 3 1}$ & $\mathbf{0 . 1 2 - 0 . 7 6}$ & $\mathbf{0 . 0 1 1}$ \\
Urbanisation sector & & & 0.039 \\
rural/urban & $\mathbf{2 . 7 3}$ & $\mathbf{1 . 2 4 - 5 . 9 7}$ & $\mathbf{0 . 0 1 2}$ \\
border/urban & $\mathbf{2 . 3 2}$ & $\mathbf{1 . 0 3 - 5 . 1 8}$ & $\mathbf{0 . 0 4}$ \\
\hline
\end{tabular}

Table I. - Odds-Ratios, $95 \%$ Confidence intervals and P-values of a full logistic regression model for the prevalence of E. multilocularis in foxes of Geneva ( $\mathrm{P} \leq 0.05$ given in bold). 


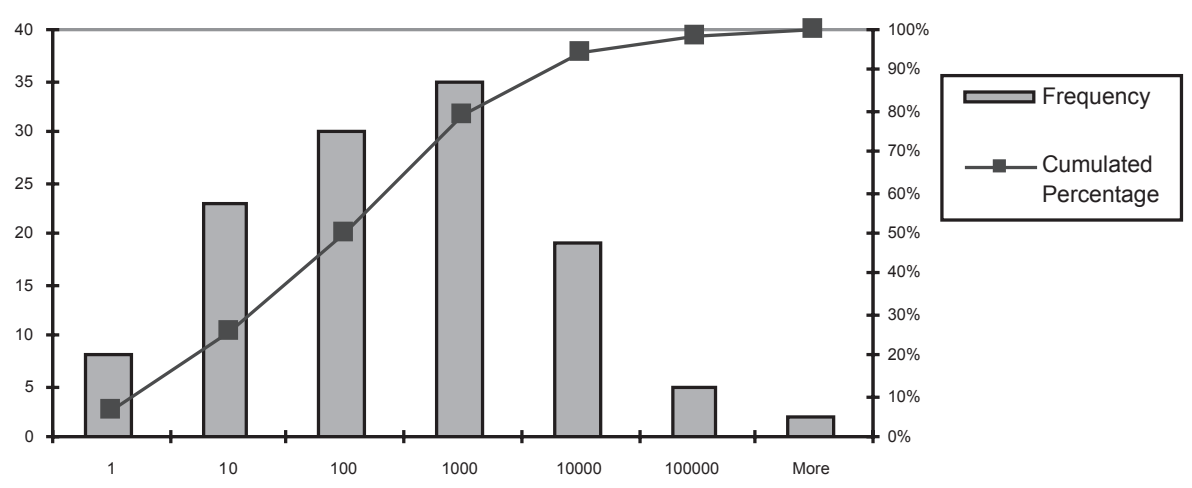

Fig. 3. - Prevalence of E. multilocularis along the increasing gradient of urbanization (represented with $95 \%$ Confidence interval).

a significance level of $\alpha \leq 0.1$ ( $\mathrm{p}=0.057)$. However, urbanisation sector remained the only significant factor (Wald Statistics 6.6, df $=2, \mathrm{p}=0.037$ ) in the model when the stepwise backward procedure was applied to the full model. Prevalence was highest in the rural (52\%, CI 43-62\%) and lowest in the urban area (31\%, CI 19-42\%; Fig. 3).

\section{INTENSITY OF INFECTION WITH E. MULTILOCULARIS}

Worm burden of E. multilocularis in foxes was highly aggregated, with a corrected moment estimate of $\mathrm{k}=$ 0.025 . Worm burden ranged from one to 120,020 specimens. Fifty percent of infected foxes harboured less

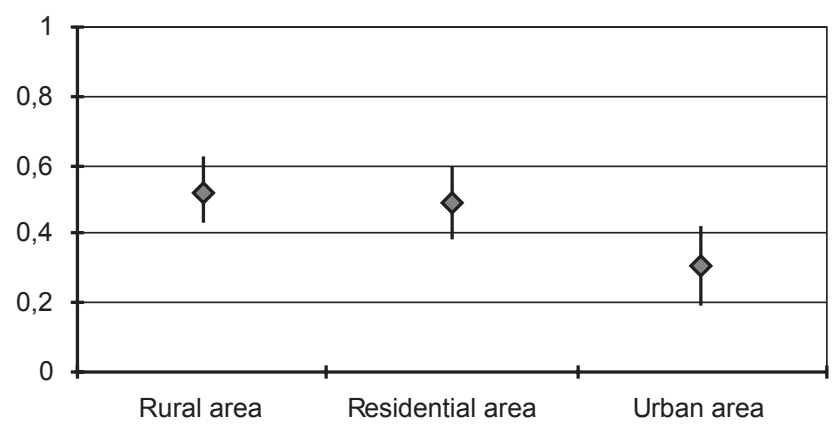

Fig. 4. - Worm burden distributions of Echinococcus multilocularis in infested red foxes (intensity of infection) from the canton of Geneva, Switzerland. than 100 worms. 26 foxes (9.7\%) had high worm burdens (more than 1,000 worms) and carried $97.3 \%$ of total worm biomass. Five foxes $(1.9 \%$ carried more than 55,000 worms, representing $75.8 \%$ of total worm burden (Fig. 4).

A significant decrease in the intensity of infection was found between rural and urban areas (Mann-Whitney U-test, $p=0.043$ ) and between residential and urban areas (Mann-Whitney test, $\mathrm{p}=0.035$; Table II).

Whereas prevalence of E. multilocularis in juveniles (prevalence of $47.7 \%$ ) and adults (prevalence of $42.9 \%$ ) presented no statistical difference, the intensity of infection was higher in juveniles than in adults (MannWhitney test, $\mathrm{p}=0.013$ ), with 64 juveniles harbouring $93.8 \%$ and 51 adults harbouring $6.2 \%$ of total worm burden. All foxes infested with more than 55,000 worms (five individuals) were juveniles from two to five and a half months-old.

\section{DISCUSSION}

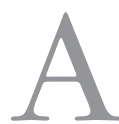

$s$ we already pointed out in a preliminary study (Fischer et al., 2003), the small-fox tapeworm is present in the canton of Geneva up to the urbanised areas of the city. Considering research conducted in neighbouring France and canton of Vaud (Switzerland) we could expect the presence of E. multilocu-

\begin{tabular}{|c|c|c|c|c|c|c|}
\hline & \multicolumn{3}{|c|}{ Adults } & \multicolumn{3}{|c|}{ Juveniles } \\
\hline & Rural area & Residential area & Urban area & Rural area & Residential area & Urban area \\
\hline Sample size* & $27(52)$ & $16(36)$ & $6(25)$ & $23(44)$ & $26(50)$ & (10 (30) \\
\hline Mean & $1,062.6$ & 417.9 & 55.5 & $12,002.1$ & $10,120.7$ & 699.1 \\
\hline Standard deviation & $4,631.5$ & 538.0 & 73.2 & $31,056.0$ & $26,885.9$ & $1,384.9$ \\
\hline Geometric mean & 45.1 & 99.2 & 21.6 & 566.0 & 182.1 & 46.7 \\
\hline Minimum & 1 & 3 & 1 & 2 & 1 & 1 \\
\hline Maximum & 24,200 & 1,798 & 199 & 120,020 & 104,000 & 4,218 \\
\hline Total worm burden & 28,690 & 6,686 & 333 & 276,048 & 263,139 & 6,992 \\
\hline $\begin{array}{l}\text { Corrected moment } \\
\text { estimate of } \mathrm{k}^{* *}\end{array}$ & 0.008 & 0.177 & 0.064 & 0.051 & 0.050 & 0.043 \\
\hline
\end{tabular}

Table II. - Worm burden distribution (intensity of infection) of E. multilocularis along the increasing gradient of urbanization, in Geneva, Switzerland. 
laris, at least in the rural areas, but the high prevalences we observed and the presence of the parasite within the city are quite astonishing. In Haute-Savoie, Contat (1984) and Pétavy et al. (1990) mention prevalences of $43 \%$ and $22 \%$ respectively over the whole "Département". In neighbouring areas of the canton of Vaud, Siegenthaler \& Brossard (1996) determined a prevalence of $11 \%$, whereas they observed a mean prevalence of $30 \%$ for the whole of western Switzerland.

The canton of Geneva is situated in the core area of the endemic range of E. multilocularis in Central Europe (Eckert \& Deplazes, 2004; Vuitton et al., 2003). In this region the prevalence was high in the nearby Jura Mountains where climatic conditions are more favourable for the survival of Echinococcus eggs, as mean temperature is rather low and humidity high (Veit et al., 1995). Siegenthaler \& Brossard op cit. observed that conditions were most favourable between 500 and $900 \mathrm{~m}$. Furthermore, landscape composition was described as playing an important role, prevalence being positively correlated to the ratio of permanent grassland, as population outbreaks of the two main intermediate hosts of E. multilocularis, Microtus arvalis and Arvicola terrestris, are favoured (Giraudoux et al., 1997; Raoul et al., 2003).

However, the prevalence of E. multilocularis in Geneva appeared to be much higher than what was observed in the adjacent areas, despite low altitude with a relatively dry and warm climate and a limited proportion of permanent grassland. This could be a sign of annual variations, or of a general increase within the last decades, as the studies mentioned (Contat op. cit. and Pétavy op. cit.) were achieved in the mid 80s and in the 90s. Furthermore, they had a supra-regional character and did not concentrate on local specificities. Thus, there might be temporal differences, dependent of the cyclic evolution of rodent populations for example, which could explain the marked difference between the rural areas of Geneva and the adjacent territories of HauteSavoie (F) and the canton of Vaud (CH).

E. multilocularis distribution is known to be heterogeneous. In Switzerland, prevalence ranges between $3 \%$ and $53 \%$ in 21 of the 23 cantons (Eckert et al., 2001a). At smaller scales, prevalence of the parasite in foxes reaches high levels in high endemic foci. A prevalence of $49 \%$ was found in the canton of Fribourg (Siegenthaler \& Brossard, 1996) and of $67 \%$ in the rural area surrounding the city of Zurich (Hofer et al., 2000). The prevalence of $45.7 \%$ in our study, reaching $68 \%$ in the rural area in 2002, indicates that Geneva can be considered as a high endemic area of the parasite.

Differences in urbanisation appeared to be the most explicative factor for differences in prevalence between foxes, when using multiple logistic regression on various potential intrinsic and extrinsic factors. The small-fox tapeworm was found up to the centre of the city of Geneva, though at a much lesser extent than in rural and residential areas. In Zurich, Hofer et al. (2000) showed a similar decrease in prevalence from the surroundings of the city to the urban zone, but they did not record any difference in worm burden distributions between rural and urban foxes, suggesting an equivalent contamination of the two habitats when comparing infested sites. In Geneva, the decrease in the intensity of infection suggests that a lower parasite biomass occurs in the urban area and thus a lower contamination characterizes the infested sites of the urban environment. These findings imply either unsuitable conditions in the city for egg survival (Urban Heat Island effect); unsuitable conditions to maintain a sustainable intermediate host population; or a different intermediate host community.

Age-related difference was revealed for the infestation rate of E. multilocularis, with juveniles infected with heavier worm burdens than adults. Higher susceptibility of juveniles suggests that an acquired but partial immunity appears in adults (Hofer et al., 2000; Raoul et al., 2003).

Compared to rural and residential areas, the urban area of the canton of Geneva may represent a less suitable habitat for rodents, especially voles. Fragmentation of the urbanized environment may result in disparate sustainable vole populations. Density of rodent population and predation rate of urban foxes on rodents might be responsible for the decrease in prevalence and at least partially for the decrease in the intensity of E. multilocularis infection. Diet of urban foxes has been investigated in several European countries (e.g. Doncaster et al., 1990; Contesse et al., 2004). Whereas rural foxes have seasonal preferences for rodents especially voles, birds, fruit and crops (Artois, 1989; Weber, 1996), urban foxes prey less frequently on small mammals and ingest more scavenged food (Contesse et al., 2004).

Finally, risk factors of the infestation of humans with E. multilocularis are reported as working in agriculture, dog ownership (Kern et al., 2004), contact with foxes (Eckert et al., 2001c) and densities of voles (Viel et al., 1999). Main route of contamination is believed to be the ingestion of eggs from contaminated soil or plants, or from direct contacts with infected definitive hosts. Prevalence in domestic carnivores is generally low but can reach relatively high levels in hyperendemic foci (Eckert \& Deplazes, 2004). However, red foxes are the main source of contamination of the environment, especially young animals (Eckert \& Deplazes, 2004). In our study, five foxes representing less than $2 \%$ of the sample carried more than $75 \%$ of the parasite biomass and were less than six month-old. One adult of twelve months-old carried more than 22,000 worms and was the only adult out of fifteen foxes har- 
bouring more than 2,000 worms. As foxes enter the city, potential risk arises for humans with the contamination of their highly used environment. An urban cycle of E. multilocularis is possible and has been recognized in the city of Zurich (Deplazes et al., 2004). Secondly, domestic animals preying on infectious rodents and living directly in the vicinity of humans represent another non-negligible, risk for humans as closer contacts occur between them and their owners (Petavy et al., 2000; Gottstein et al., 2001; Deplazes et al., 2004). The concern about a potential increase of the infection risk for human population with E. multilocularis eggs has led to trials to control this zoonosis. In Germany, mass treatment of red foxes with baits containing praziquantel was applied using light aircrafts (Romig et al., 1999). In the city of Zurich, where a high contamination with E. multilocularis was identified (Stieger et al., 2002), a more intensive but locally restricted strategy for urban areas was tested (Hegglin et al., 2003). As observed in many studies (Hofer et al., 2000; Eckert et al., 2001a; Hansen et al., 2003), and also in Geneva, juvenile foxes have a significantly higher worm burden than adults. Furthermore, they defecate within a restricted area around the reproductive den during their first months of life. Environmental contamination with eggs in this area is thus likely to be very elevated. In Geneva, we observed several reproductive dens located in or close to gardens of family houses with children. These gardens are thus primary risk areas, and we suggest that they should be considered as a priority when planing treatment strategies.

\section{ACKNOWLEDGEMENTS}

W e acknowledge the support of our research activities by the Swiss Federal Office for Education and Science (EU FAIR Projekt CT973515/BBW Nr. 97.0586), and the European Commission (Project Echinorisk, Contract QLK2-CT-2001-01995) and by the Service des Forêts, de la Protection de la Nature et du Paysage (SFPNP) and the Service Vétérinaire of the canton of Geneva.

\section{REFERENCES}

Artois M., Stahl P., Leger F., Morvan P. \& Barbillon E. Prédation des rongeurs par le renard roux (Vulpes vulpes) en Lorraine. Gibier Faune Sauvage, 1989, 6, 279-294.

Breitenmoser U., Kaphegyi T., Kappeler A. \& Zanoni R. Significance of young foxes for the persistence of rabies in Northwestern Switzerland, in: Proceedings of the $3^{\text {rd }}$ Congress of the European Society of Veterinary Virology. Schwyzer M., Ackermann M., Bertoni G., Kocherhans R., Mc Cullough K., Wittek R. \& Zanoni R. (eds), Immunbiology of Viral Infections, 1995, 391-396.
Chautan M., Pontier D. \& Artois M. Role of rabies in recent demographic changes in red fox (Vulpes vulpes) populations in Europe. Mammalia, 2000, 64 (4), 391-410.

Contat F. Contribution à l'étude épidémiologique de l'échinococcose alvéolaire en Haute-Savoie. Étude histologique des lésions. Thèse de médecine vétérinaire, 1984, Lyon, 190 pages.

Contesse P., Hegglin D., Gloor S., Bontadina F. \& Deplazes P. The diet of urban foxes (Vulpes vulpes) and the availability of anthropogenic food in the city of Zurich, Switzerland. Mammalian Biology, 2004, 69 (2), 81-95.

Deplazes P., Hegglin D., Gloor S. \& Romig T. Wilderness in the city: the urbanization of Echinococcus multilocularis. Trends in Parasitology, 2004, 20 (2), 77-84.

Doncaster C.P., Dickman C.R. \& Macdonald D.W. Feeding ecology of red foxes (Vulpes vulpes) in the city of Oxford, England. Journal of Mammalogy, 1990, 71 (2), 188-194.

ECKert J. \& Deplazes P. Biological, epidemiological, and clinical aspects of Echinococcosis, a zoonosis of increasing concern. Clinical Microbiology Reviews, 2004, 17 (1), 107135.

Eckert J., Rausch R.L., Gemmell M.A., Giraudoux P., Kamiya M., Liu F.J., Schantz P.M. \& Romig T. Epidemiology of Echinococcus multilocularis, Echinococcus vogeli, and Echinococcus oligarthrus, in: WHO OIE Manual on echinococcosis in humans and animals, 2001a, 164-194.

Eckert J., Gottstein B., Heath D. \& Liu F.J. Prevention of echinococcosis in humans and safety precautions, in: WHO OIE Manual on echinococcosis in humans and animals, 2001c, 238-247.

ELLIOT J.M. Statistical analysis of samples of benthic invertebrates. Ambleside, Freshwater Biological Association, 1977.

Fischer C., Reperant L., Weber J.M., Ochs H. \& Deplazes P. Relation in the presence of various parasites in the red fox (Vulpes vulpes) in Geneva. Swiss Medical Weekly, 2003, 133, 61.

Giraudoux P., Delattre P., Habert M., Quéré J.P., Deblay S., Defaut R., Duhamel R., Moissenet M.F., Salvi D. \& TruCHETET D. Population dynamics of fossorial water vole (Arvicola terrestris scherman): a land usage and landscape perspective. Agiculture, Ecosystems and Environment, 1997, 66, 47-60.

Giraudoux P., Raoul F., Bardonnet K., Vuillaume P., Tourneux F., Cliguet F., Delattre P. \& Vuitton D.A. Alveolar echinococcosis: characteristics of a possible emergence and new perspectives in epidemiosurveillance. Médecine des Maladies Infectieuses, 2001, 31 (suppl. 2), 247-256.

Gloor S., Bontadina F., Hegglin D., Deplazes P. \& BreitenMOSER U. The rise of urban fox populations in Switzerland. Mammalian Biology, 2001a, 66, 155-164.

Gloor S., Bontadina F., Hegglin D. \& Hotz T. Füchse im Siedlungsraum. Wildbiologie in der Schweiz, 2001b, 6 (32), 23 pages.

GotTstein B. Echinococcus multilocularis infection: immunology and immunodiagnosis. Advances in Parasitology, 1992, 31, 321-380.

Gottstein B., Saucy F., Deplazes P., Reichen J., Demierre G., Busato A., Zuercher C. \& Pugin P. Is high prevalence of 
Echinococcus multilocularis in wild and domestic animals associated with disease incidence in Humans? Emerging Infectious Diseases, 2001, 7 (3).

Hansen F., Tackmann K., Jeltsch F., Wissel C. \& Thulke H.H. Controlling Echinococcus multilocularis - Ecological implications of field trials. Preventive Veterinary Medicine, 2003, 60 (1), 91-105.

HARRIS S. The food of suburban foxes (Vulpes vulpes) with special reference to London. Mammal Review, 1981, 11 (4), 151-168.

Hegglin D., Ward P. \& Deplazes P. Anthelmintic baiting of foxes against urban contamination with Echinococcus multilocularis. Emerging Infectious Diseases, 2003, 9, 12661272 .

Hofer S., Gloor S., Müller U., Mathis A., Hegglin D. \& Deplazes P. High prevalence of Echinococcus multilocularis in urban red foxes (Vulpes vulpes) and voles (Arvicola terrestris) in the city of Zurich, Switzerland. Parasitology, 2000, 120, 135-142.

Kern P., Ammon A., Kron M., Sinn G., Sander S., Petersen L.R., GAUS W. \& KERN P. Risk factors for alveolar echinococcosis in humans. Emerging Infections Diseases, 2004, 10, (12).

Macdonald D.W. \& Newdick M.T. The distribution and ecology of foxes, Vulpes vulpes (L.), in urban areas, in: Proceedings of the $2^{\text {nd }}$ European Ecological Symposium: Urban Ecology. Bornkamm R., Lee J.A. \& Seeward M.R. (eds). Blackwell Scientific Publications, Oxford, 1982, 123-135.

Petavy A.F., Deblock S. \& Prost C. Épidémiologie de l'échinococcose alvéolaire en France. I. - Helminthes intestinaux du renard commun (Vulpes vulpes L.) en Haute-Savoie. Annales de Parasitologie Humaine et Comparée, 1990, 65 (1), 22-27.

Petavy A.F., Tenora F., Deblock S. \& Sergent V. Echinococcus multilocularis in domestic cats in France: a potential risk factor for alveolar hydatic disease contamination in humans. Veterinary Parasitology, 2000, 89 (2-3), 151-156.

Raoul F., Michelat D., Ordinaire M., Décoté Y., Aubert M., Delattre P., Deplazes P. \& Giraudoux P. Echinococcus multilocularis: secondary poisoning of fox population during a vole outbreak reduces environmental contamination in a high endemicity area. International Journal for Parasitology, 2003, 33 (9), 945-954.

Romig T., Bilger B., Merli M., Dinkel A., Lucius R. \& MaCKENSTEDT U. Bekämpfung von Echinococcus multilocularis in einem Hochendemiegebiet Süddeutschlands, in: Neuere Methoden und Ergebnisse zur Epidemiologie von Parasitosen. Tagung der Fachgruppe Parasitologie und parasitäre Krankheiten. Deutsche Veterinärmedizinische Gesellschaft, Giessen, Germany, 1999, 172-183.

SHASHUA-BAR L. \& HOFFMAN M.E. Vegetation as a climatic component in the design of an urban street; an empirical model for predicting the cooling effect of urban green areas with trees. Energy and Buildings, 2000, 31 (3), 221-235.

Siegenthaler M. \& Brossard M. Infection du renard par Echinococcus multilocularis dans le canton de Vaud. Rapport final, 1996, 7 pages + annexes.

Stieger C., Hegglin D., Schwarzenbach G., Mathis A. \& DeplaZES P. Spatial and temporal aspects of urban transmission of Echinococcus multilocularis. Parasitology, 2002, 124, 631-640.

Unger J., SÜMeghy Z. \& ZoBOKI J. Temperature cross-section features in an urban area. Atmospheric Research, 2001, 58 (2), 117-127.

Veit, P., Bilger B., Schad V., Schäfer J., Frank W. \& Lucius R. Influence of environmental factors on the infective Echinococcus multilocularis eggs. Parasitology, 1995, 110, 7986.

Viel J.F., Giraudoux P., Abrial V. \& Bresson-Hadni S. Water vole (Arvicola terrestris scherman) density as risk factor for human alveolar echinococcosis. American Journal of Tropical Medicine \& Hygiene, 1999, 61, 559-565.

Vuitton D.A., Zhou H, Bresson-Hadni S., Wang Q., PiarRoux M., Raoul F. \& Giraudoux P. Epidemiology of alveolar echinococcosis with particular reference to China and Europe. Parasitology, 2003, 127, S87-S107.

WANDELER A.I. Altersbestimmung bei Füchsen. Revue Suisse de Zoologie, 1976, 83, 956-963.

WeBer J.M. Food selection by adult red foxes Vulpes vulpes during a water vole decline. Wildlife Biology, 1996, 2 (4), 283-288.

WORTON B.J. Kernel methods for estimating the utilization distribution in home-range studies. Ecology, 1989, 70 (1), 164168.

Reçu le 17 février 2005 Accepté le 13 septembre 2005 